\title{
Judicial Decision Making: A Dynamic Reputation Approach
}

\section{Citation}

Alma Cohen, Alon Klement \& Zvika Neeman, Judicial Decision Making: A Dynamic Reputation Approach, J. Legal Stud. (forthcoming 2015).

\section{Permanent link}

http://nrs.harvard.edu/urn-3:HUL.InstRepos:16073955

\section{Terms of Use}

This article was downloaded from Harvard University's DASH repository, and is made available under the terms and conditions applicable to Open Access Policy Articles, as set forth at http:// nrs.harvard.edu/urn-3:HUL.InstRepos:dash.current.terms-of-use\#OAP

\section{Share Your Story}

The Harvard community has made this article openly available.

Please share how this access benefits you. Submit a story.

\section{Accessibility}




\section{HARVARD}

JOHN M. OLIN CENTER FOR LAW, ECONOMICS, AND BUSINESS

JUDICIAL DECISION MAKING: A DYNAMIC REPUTATION APPROACH

Alma Cohen

Alon Klement

Zvika Neeman

Forthcoming, Journal of Legal Studies, Volume 44, 2015

Discussion Paper No. 803

$1 / 2015$

Harvard Law School

Cambridge, MA 02138

This paper can be downloaded without charge from:

The Harvard John M. Olin Discussion Paper Series:

http://www.law.harvard.edu/programs/olin_center/

The Social Science Research Network Electronic Paper Collection:

http://ssrn.com/abstract=2559211 


\title{
Judicial Decision Making: A Dynamic Reputation Approach*
}

\author{
Alma Cohen $^{\dagger} \quad$ Alon Klement ${ }^{\ddagger} \quad$ Zvika Neeman $^{\S}$
}

\begin{abstract}
We seek to contribute to an understanding of how judicial elections affect the incentives and decisions of judges. We develop a theoretical model suggesting that judges who are concerned about their reputation would tend to "decide against their prior" as they approach elections. That is, judges who imposed a large number of severe sentences in the past, and are thus perceived to be strict, would tend to impose less severe sentences prior to elections, and judges who imposed a large number of light sentences in the past, and are perceived to be lenient, would tend to impose more severe sentences prior to elections. Using data from the Pennsylvania Commission on Sentencing (PCS), we test, and find evidence consistent with, the predictions of our model.

JEL Classification Codes: D82, K40, K41.
\end{abstract}

\section{Introduction}

In their book, The Behavior of Federal Judges, Epstein, Landes and Posner (henceforth, ELP) contrast two alternative theories of judicial behavior: the legalistic theory, which assumes that judges decide cases in accordance with orthodox norms of judicial decision-making; and the realistic theory, which conjectures that judges, like other economic agents, decide cases according to their preferences and incentives. Following the latter approach, the book suggests a labor market model for judicial behavior, and presents a comprehensive empirical examination of this model. The book concludes that the model provides a convincing account of actual judicial behavior.

In this paper we follow the realistic approach as well, and we seek to contribute to an understanding of how incentives and preferences influence judicial decisions. In particular, we put forward a dynamic approach to the analysis of decision making by judges that face elections. Instead of aggregating the decisions of each judge over time, we propose instead to consider how different

\footnotetext{
*We thank Ronen Avraham and seminar participants at the IDC, Yale Law School, and the Conference on "A Rational Choice Approach to Judging" at the University of Chicago. Zvika Messing and Roni Shani provided excellent research assistance. Financial support from the Foerder Institute and Sapir Institute at Tel Aviv University, the IDC, and Harvard Law School is gratefully acknowledged. Finally, we are grateful to Constantine Boussalis from the Harvard Law School Library for helping us obtain the data from the Pennsylvania Sentencing Commission, and to Donna VanBourgondien from the Pennsylvania Department of State, Bureau of Commissions, Elections and Legislation, for helping us obtain the data on Pennsylvania Judicial Election outcomes.

${ }^{\dagger}$ Harvard Law School; Berglas School of Economics, Tel Aviv University, Israel; and the NBER

$\ddagger$ Radzyner School of Law, Interdisciplinary Center Herzliya, Israel

$\S$ Berglas School of Economics, Tel Aviv University, Israel
} 
decisions of the same judge vary over the election cycle and in particular, how decisions are influenced by the past decisions of the judge. This approach, we suggest, can generate theoretical and empirical insights.

Our approach is based on a dynamic reputation model of judicial behavior, which differs from the static, labor market model, that is proposed by ELP. Reputation models assume that an agent (in this case a judge) holds private information about some of the agent's characteristics. A principal (in this case, the general public, or any other audience that affects the judge's future welfare) does not know this information. The principal's belief over the agent's characteristics is updated based on the agent's observed actions. In such a setting, the agent may make choices aimed at establishing a reputation that would increase the agent's long term payoffs. Since decisions are made repeatedly over time, the agent's present decision depends on past observed decisions. ${ }^{1}$

In a previous paper (Klement and Neeman, 2013), two of us showed that arbitrators, who may be vetoed by the litigants upon being offered to arbitrate a specific case, may try to establish a reputation for being neutral and unbiased. To establish such a reputation, arbitrators may deliver decisions they know to be incorrect. In particular, we identified a possible conflict between the positive selection effect that is induced by allowing litigants to veto arbitrators based on information about their past Win/Loss ratios, and the negative incentive effect that is induced by such selection. Whereas selection allows screening of biased arbitrators, incentive effects may cause unbiased arbitrators to deliver incorrect decisions, in order to avoid a bad reputation for being biased. ${ }^{2}$

We suggest that similar reputational considerations may implicate judicial decision making in those circumstances where judges stand for reelection or reappointment. We present a simple model in which a judge is asked to apply her discretion in sentencing a convicted felon. The judge may either impose a light or a severe sentence. The judge knows what the general public's preferred sentence would be in each specific case, given the factual and legal circumstances of the case. Judges are either lenient, or strict, representing their idiosyncratic beliefs and sentencing preferences. Thus, lenient judges prefer to give lighter sentences, and strict judges prefer to give more severe sentences. The general public does not know the exact details of each specific case, and it only observes the actual sentence handed by the judge. The public has some preferences over the type of judges, which is implied from its preference over sentences. In the model we assume that the preferences of the public and of strict judges are aligned, and therefore that the public prefers strict judges. Our conclusions, however, continue to hold under the opposite assumption.

As we show, in equilibrium, both lenient and strict judges' sentencing decisions are affected by their concern for reputation. As may be expected, given the assumption that the public prefers strict judges, both types of judges tend to deliver more severe sentences than they would have delivered absent reputation concerns. However, a judge's sentencing decisions depend on her prior sentencing history in a way that is more nuanced. As a judge's reputation for being lenient becomes stronger, she would choose more severe sentences prior to elections. On the other hand, if a judge's

\footnotetext{
${ }^{1}$ For a comprehensive review of reputation models in economics see Mailath and Samuelson (2006).

${ }^{2}$ For a general model of Bad Reputation see Ely and Valimaki, 2003. As we explained, however, a more comprehensive model of arbitrator reputation would also account for favorable reputation effects, which may induce biased arbitrators to deliver appropriate decisions in an effort to favorably impress future litigants and convince them they are unbiased.
} 
reputation for being strict is sufficiently strong, she would impose less severe sentences prior to elections, as she would be less concerned about "convincing" the public that she is not lenient. Thus, our analysis suggest that sentencing decisions would be negatively serially correlated. Interestingly, even if the public is assumed to have a preference against lenient judges, this does not imply that judges would render as sentences that are as high as they can. Judges are expected to "balance" two types of preferences - their preference over the sentence they would give in a specific case, and their interest in getting reelected. As a judge's reputation for being strict becomes stronger, her sentencing behavior is expected to be less affected by her reputational concerns and more by her preference regarding the appropriate sentence in the specific case before her.

We test empirically the theoretical predictions produced by our model. To this end, we use data on sentencing decisions by elected Pennsylvania Common Pleas Court judges between 2001 and 2010. We indeed find significant negative correlation when we interact a judge's prior decisions with her proximity to reelection. Furthermore, we find that this correlation is significant only for judges in the first ten years of their judicial term. After being reelected, judges do not exhibit any such correlation. In our reputation model terminology, judges who have already established reputation for being strict, are less concerned that any single decision would change how they are perceived by the public. Those judges therefore impose sentences according to their judicial preferences, without trying to convince the public that they are not lenient. Our empirical findings are therefore consistent with the predictions of the dynamic reputation model we develop.

The paper proceeds as follows: Section 2 presents a short review of the literature on the effect of judicial elections on judicial decisions; Section 3 presents the theoretic reputation model; Section 4 provides an empirical examination of the model; Section 5 concludes.

\section{Related Literature}

Election and appointment of judges may impact their decisions in two ways - indirectly, through selection, and directly, by affecting their incentives. Selection effects imply that judges attitudes resemble those of their appointing body, be it the state governor, an appointment committee, or the public at large. Both initial appointment of judges, and their retention or reappointment may serve to screen out judges whose attitudes do not conform sufficiently with the electing body's approach. Incentive effects imply that judges would decide cases in ways that increase their chances to be reappointed. If judges expect to be screened based on their judicial decisions, they may consider this when rendering those decisions. The two effects are not easy to distinguish empirically.

Many studies have demonstrated the effect of reelection and reappointment on judicial decisionmaking. Shephard, 2011, provides a concise review of this literature. Three hypotheses emerge from the literature: First, that judges' decisions conform with the preferences of their appointing agents (see, e.g., Hall 1992 and 1995; Brace and Hall 1997; and Shephard 2009, 2009a, 2009b). Second, that the degree of such conformity depends on various institutional features of the method of reappointment (whether reappointment decisions are made by some gubernatorial or legislative body or through public elections, e.g. Brace and Boyea, 2008; Boyea, 2010; Choi, Gulati and Posner, 2010; 
Lim, 2013; and if made through elections, whether these are competitive and whether they are held on a partisan or non-partisan basis, e.g. Helland and Tabarrock, 2002; Gordon and Huber 2007; Caldarone et. al. 2009). These two hypotheses do not distinguish between selection and incentive effects. The third hypothesis does. It suggests that the conformity between the preferences of the judge and her appointing agent becomes more pronounced as reappointment or reelection approaches, and that it becomes less pronounced when judges are serving their last term in office (see e.g. Brooks and Raphael, 2002; Huber and Gordon, 2004; Gordon and Huber, 2007; Shephard 2009, 2009a, 2009b; Lim, 2013).

Our analysis focuses on the incentive effect of judicial elections. To do so, we examine how a judge's sentencing decision depends on her history of previous sentencing decisions. We suggest that such dependence may be explained by a reputation model. Two papers that are most proximate in their theoretical approach to ours are Huber and Gordon, 2007a, and Lim, 2013. Huber and Gordon, 2007a presents a multi-stage dynamic model in which legislators set sentencing boundaries first, then judges impose their preferred sentences, and finally, the electorate decides whether to retain the judge for another judicial term. Their model assumes that judges have private information regarding their type, and the appropriate sentence. In equilibrium, judges deviate from their preferred sentence in order to increase their probability of getting reelected. These features are applied also in our model. However, unlike Huber and Gordon, our model analyzes the effect of different prior public beliefs on judges' sentencing behavior. This allows us to develop subtler conjectures about the dependence between a judge's sentence and her prior sentencing history, and to examine these conjecture empirically.

Lim, 2013, presents a dynamic structural empirical model in which she estimates judges' preferences over sentencing, against their benefits from being reelected. She uses sentencing data from Kansas, which contains within state variation of judicial selection methods, that are either by appointment or by election. The structural model allows her to distinguish selection effects, which are more pronounced when judges are appointed by government officials, from incentive effects, which play significant role when judges are elected. Her model, too, does not analyze the dependence of present sentencing decisions on previous sentencing history.

Finally, there is some literature on Supreme Court Justices' preference changing (or 'ideological drift') over time (e.g. Epstein et al. 1998, Martin and Quinn, 2002, 2007). This literature, however, should be distinguished from the current paper, which analyzes dynamic decision making, namely, the dependence of a judge's decision on her prior decisions.

\section{A Model of Judicial Reputation}

\subsection{The Model}

Consider the problem of a judge who has to sentence a convicted offender. For simplicity, we assume that the sentence can be either light or severe. The general public has some preference over 
the severity of a sentence in each case - the appropriate sentence in this case - ${ }^{3}$ depending on the exact details of the case. ${ }^{4}$ However, the public is not informed about the details of each case and therefore it only knows that the appropriate sentence is severe with an ex-ante probability $q \in[0,1]$, independently across all cases. Thus, $q$ reflects the public's preference for severe sentences over all cases.

Judges observe the exact details of each case and therefore know what is the public's preferred sentence. There are two types of judges - strict and lenient. A strict judge's preferences are aligned with the public's preferences, and she therefore obtains a payoff of one if she renders the appropriate sentence (light or severe) and a payoff of zero otherwise. A lenient judge finds it hard to impose a severe sentence. We assume she obtains a payoff of one if she renders a light sentence and a payoff of zero otherwise. ${ }^{5}$

We assume that in addition to the payoff that a judge derives from the sentence she renders, she also cares about her chances of reappointment. We denote the value of being reappointed by $V>1$ and assume that it is commonly believed that the likelihood of reappointment, denoted $f\left(\pi_{S}\right)$, is increasing and concave in the probability with which the judge is believed to be strict, denoted $\pi_{S}$. Furthermore, we assume that the value of reappointment $V$ is sufficiently high to induce judges to sometimes render a decision which does not conform with their sentencing preferences, when such a decision increases their chance of reappointment. Thus, the long term interests of a judge in reappointment may be sufficiently strong to overcome her short term interests in rendering her preferred sentence, depending on her type.

We denote the prior probability with which the public believes the judge to be strict and lenient by $\pi_{S}, \pi_{L}=1-\pi_{S}$, respectively. This prior probability is determined by the judge's individual characteristics (such as race, gender, family situation, her professional record prior to being elected to the judicial office, etc.) and by her history of past decisions. In general, the information gleaned from one additional decision depends not only on the prior probability, but also on the length of history on which this prior probability is based. The information inferred from one additional decision would not lead to a posterior probability that is significantly different from the prior probability if the number of the judge's previous decisions is large, but may lead to a significantly different posterior belief if the number of the judge's previous decisions is small. In other words, the prior belief about a judge who has made a large number of previous decisions can be thought of as "strong" and more resistant to change, while the prior belief about a judge who has made a small number of previous decisions can be thought of as "weak" and more susceptible to change. For simplicity, we abstract away from this consideration in the formal analysis below.

\footnotetext{
${ }^{3}$ The terminology is borrowed from the Pennsylvania Sentencing Guidelines. See section 303.1 which reads "The court shall consider the sentencing guidelines in determining the appropriate sentence for offenders convicted of, or pleading guilty or nolo contendere to, felonies and misdemeanors...".

${ }^{4}$ Notice that the public is not assumed to always want the sentence to be severe. See Cullen, Fisher and Applegate, 2000.

${ }^{5}$ The assumption that the public's preferences are aligned with those of the 'strict' judge is made only for expositional convenience, and expresses no normative judgment as to what the sentence should be. Our results also hold if we assume the opposite - namely, that the lenient judge's preferences are those which are aligned with the public's preferences, whereas the strict judge prefers to always render a severe judgment, except that instead of distorting their decisions upwards, judges in this case would tend to distort their decisions downwards.
} 


\subsection{Analysis}

A judge has four pure strategies available: impose a severe sentence independent of the publicly preferred - appropriate - sentence; impose a light sentence independent of the appropriate sentence; impose an appropriate sentence; and impose an (always) inappropriate sentence. A judge also has mixed strategies available. A mixed strategy can be described by two probabilities, $p_{l}$ and $p_{s}$, which denote the probability of imposing the appropriate sentence when a light and severe sentence is appropriate, respectively. A strategy of a strict judge is denoted by a pair $\left(p_{l}^{S}, p_{s}^{S}\right)$, and a strategy of a lenient judge is denoted by a pair $\left(p_{l}^{L}, p_{s}^{L}\right)$.

The next observation follows from our assumption about judges' preferences.

Claim 1. In equilibrium, a lenient judge always renders a (weakly) lighter sentence than a strict judge, for every prior belief $\pi_{S} \in[0,1]$.

Proof. A judicial decision generates an immediate benefit and a future benefit that depends on its effect on the judge's chances of reappointment. The public's posterior belief about the judge's type depends on the sentence imposed by the judge, but not on the judge's type, which is not known by the public. This implies that the future benefit from any decision is independent of the judge's true type. Since a lenient judge derives a larger immediate benefit from a lighter sentence, she will impose a (weakly) lighter sentence than a strict judge.

Corollary. The publicly preferred judicial behavior, in which judges always give the publicly preferred - appropriate - sentence regardless of their type, cannot be sustained as equilibrium behavior.

Proof. If judges always give the appropriate sentence, then the public learns nothing about a judge's type from the judge's decision. This means that judges' decisions do not affect their chances of being reappointed. Thus, a lenient judge who deviates and imposes a light sentence when a severe sentence is due is not sanctioned for his deviation.

Next, we show that reputational considerations imply that simply following the judge's preferred sentence, given the appropriate sentence in a specific case, cannot be sustained in equilibrium either.

Claim 2. For every prior belief, $\pi_{S} \in(0,1)$, if $V$ is sufficiently high then a lenient judge would sometimes render a severe sentence and a strict judge would sometimes render an a severe sentence where the publicly preferred - appropriate - sentence is light.

Proof. Fix $\pi_{S} \in(0,1)$. By claim 1, imposition of a light sentence implies a (weakly) lower posterior probability that the judge is strict. Therefore, if a strict judge cares enough about reappointment, she would prefer to give a severe sentence than an appropriate light sentence. Similarly, a lenient judge that cares enough about reappointment would prefer to render a severe sentence than a light sentence. 
We describe a mixed strategy equilibrium that gives rise to both good and bad reputational forces as described above. ${ }^{6}$ For large values of the prior belief $\pi_{S}$, greater than a threshold value $\bar{\pi}_{S}$, strict judges impose the publicly preferred - appropriate - sentence and lenient judges always impose a light sentence. In this range the concavity of $f$ implies that the inference that the judge is more likely to be lenient after a light sentence has a smaller effect on the likelihood of being reappointed. For small values of the prior belief $\pi_{S}$, that fall below the threshold $\bar{\pi}_{S}$, the inference that the judge is more likely to be lenient after a light sentence has a large negative effect on the likelihood of being reelected. In this range, strict judges always impose a severe sentence when it is due (that is, $p_{s}^{S}=1$ ) but when a light sentence is due, they impose a light sentence with probability $p_{l}^{S}<1$; lenient judges always impose a light sentence when it is due (that is, $p_{l}^{L}=1$ ) but when a severe sentence is due, they impose a severe sentence only with probability $p_{s}^{L}<1$.

For this behavior to be indeed a part of an equilibrium, strict and lenient judges have to be indifferent between rendering a severe and light sentence when a light and a severe sentence is due, respectively. This means that the probabilities $p_{l}^{S}$ and $p_{s}^{L}$ have to satisfy the following equation:

$$
1+f\left(\pi_{S}^{\prime}\right) V=f\left(\pi_{S}^{\prime \prime}\right) V
$$

where $\pi_{S}^{\prime}=\frac{\pi_{S}(1-q) p_{l}^{S}}{\pi_{S}(1-q) p_{l}^{S}+\pi_{L}\left(1-q+q\left(1-p_{s}^{L}\right)\right)}<\pi_{S}$ denotes the posterior probability that the judge is strict after a light sentence, and $\pi_{S}^{\prime \prime}=\frac{\pi_{S}\left(q+(1-q)\left(1-p_{l}^{S}\right)\right)}{\pi_{S}\left(q+(1-q)\left(1-p_{l}^{S}\right)\right)+\pi_{L} q p_{S}^{L}}>\pi_{S}>\pi_{S}^{\prime}$ denotes the posterior probability that the judge is strict after a severe sentence. ${ }^{7}$

It is possible to construct other mixed strategy equilibria in which competent lenient judges mix both when a severe and a light sentence are due. If, however, a lenient judge prefers to mix when a severe sentence is due rather than when a light sentence is due, all such equilibria are eliminated. Indeed, imposition of this as an additional assumption so that instead of deriving a payoff of 1 from rendering a light decision, a lenient judge would obtain a payoff of $1+\epsilon$ for some small $\epsilon>0$ from rendering a light decision when it is appropriate and a payoff of 1 when the appropriate sentence is severe, would eliminate these other equilibria. ${ }^{8}$

\footnotetext{
${ }^{6}$ Since each type of judge has four pure strategies available, there are sixteen different potential pure strategy equilibrium combinations. Only two out of these sixteen combinations can be sustained as a pure strategy equilibrium - for both types of judges to always impose a light sentence, or for both of them to always impose a severe sentence. Both equilibria are sustained by the public's (off the equilibrium) belief that any deviation indicates that the judge is lenient. We find these two pure strategy equilibria to be less interesting because in practice judges' decisions do vary with the particulars of the cases they are deciding. Furthermore, these two equilibria are inconsistent with the assumption that the probability of a judge's reappointment is increasing in $\pi_{S}$ because in these equilibria the judge's sentence is independent of $\pi_{S}$. Moreover, the equilibrium where judges always impose a light sentence fails a version of the intuitive criterion (Cho and Kreps, 1987).

${ }^{7}$ In general, the indifference conditions for a strict and a lenient judge would be different. Their identity here is an outcome of our assumptions about judges' payoffs.

${ }^{8}$ The argument is as follows: Recall that in a mixed strategy equilibrium a judge must be indifferent between rendering a light and a severe sentence. Claim 1 implies that the posterior belief that a judge is lenient is smaller than or equal to the prior belief following a light sentence, and that the posterior belief that a judge is strict is larger than or equal to the prior belief following a severe sentence. It therefore follows that a strict judge cannot be indifferent between imposing a light sentence and a severe sentence when a severe sentence is due. Thus, it must be that in equilibrium a strict judge always renders a severe sentence when it is due and she mixes only when a light sentence is due.

In equilibrium, a lenient judge cannot mix when a light sentence is due because once we change the payoffs slightly as
} 
The next proposition summarizes the empirical implications of the mixed strategy equilibrium described above.

Proposition. Ceteris Paribus, judges exhibit a tendency to decide "against their prior." Specifically,

1. A strict judge who has imposed a large number of severe sentences in the past and so has a strong reputation for being strict (i.e., $\pi_{S}>\bar{\pi}_{S}$ ) imposes the publicly preferred - appropriate - sentence, which on average implies she imposes shorter sentences than she does after a large number of light sentences in which case $\pi_{S}<\bar{\pi}_{S}$. A strict judge who has imposed a large number of light sentences in the past and so has a strong reputation for being lenient (i.e., $\pi_{S}<\bar{\pi}_{S}$ ) mixes and imposes a severe sentence when she thinks it is the publicly preferred - appropriate - sentence, and sometimes also when she thinks it is not. Thus, on average she imposes longer sentences than she does after a large number of severe sentences.

2. A lenient judge who has imposed a large number of severe sentences in the past and so has a strong reputation for being strict (i.e., $\pi_{S}>\bar{\pi}_{S}$ ) always imposes a light sentence, which implies she imposes shorter sentences than she does after a large number of light sentences in which case $\pi_{S}<\bar{\pi}_{S}$. A lenient judge who has imposed a large number of light sentences in the past and so has a strong reputation for being lenient (i.e., $\pi_{S}<\bar{\pi}_{S}$ ) mixes and sometimes imposes a severe sentence when such a sentence is appropriate according to the public's preferences. Thus, on average she imposes longer sentences than she does after a large number of severe sentences where she always imposes a light sentence.

3. The tendency to decide "against the prior" should become weaker, as the value of reappointment becomes smaller.

Proof. The proof follows from the construction of the mixed strategy equilibrium. A strict judge with prior $\pi_{S}>\pi_{S}$ imposes the publicly preferred - appropriate - sentence, which is shorter, on average, than the average sentence she imposes in equilibrium for $\pi_{S}<\bar{\pi}_{S}$. A lenient judge with prior $\pi_{S}>\pi_{S}$ imposes a light sentence, which is shorter, on average, than the average sentence she imposes in equilibrium for $\pi_{S}<\bar{\pi}_{S}$. And, by Claim 1, strict judges render more severe sentences than lenient judges, so Bayesian updating implies that a judge who has imposed a large number of severe sentences in the past has a reputation for being strict, or such that $\pi_{S}>\bar{\pi}_{S}$, and a judge who has imposed a large number of light sentences in the past has a reputation for being strict, or such that $\pi_{S}<\bar{\pi}_{S}$.

The threshold $\bar{\pi}_{S}$ that determines the point at which judges decide according to their short term interest only is determined by the equation $1+f\left(\pi_{S}^{\prime}\right) V=f\left(\pi_{S}^{\prime \prime}\right) V$. The concavity of the function $f$ implies that the threshold is increasing in $V$. That is, the lower is $V$, the lower is the weight that

explained in the main text it cannot be that both lenient and strict judges are indifferent between imposing a light and a severe sentence when a light sentence is due. 
the judges puts on her likelihood of reelection, the bigger the weight she puts on maximization of her short term interests, and the lower is the threshold prior beyond which she ignores the effect of her decisions on her probability of reelection.

As mentioned above, for simplicity we did not distinguish between judges who have long histories of decisions and for whom the information conveyed by one additional decision is small, and judges who have short histories of decisions and for whom the information conveyed by one additional decision is large. Intuitively, since the effect of any single sentence on the reputation of judges is decreasing the more previous decisions a judge has made, a judge's tendency to decide "against the prior" should also decrease in the number of sentences she renders. This is due to the fact that if a judge's decision has only a small effect on her likelihood of reelection, the threshold beyond which she decides according to her short-term interests is very low, and approaching zero if her decision has no effect on the probability of reelection. This implies that the tendency to decide against the prior, which hinges on the difference in judges' behavior below and above the threshold loses much of its power because the chance that it would be manifested becomes smaller.

\section{Empirical Examination of Pennsylvania Sentencing Decisions}

\subsection{Data}

We use sentencing data from the Pennsylvania Commission on Sentencing (PCS). Our dataset covers the ten-year period between 2001 and 2010, and it includes all felony and misdemeanor offenses in which the offender was convicted and then sentenced by the Pennsylvania Court of Common Pleas. ${ }^{9}$ Criminal cases are assigned among the 60 judicial districts following Pennsylvania venue rules, according to the place where the crime was committed. ${ }^{10}$ Ordinarily, every sentence must be imposed within 90 days of conviction or the entry of a plea of guilty or nolo contendere, ${ }^{11}$ and reported by the judge to the Commission on Sentencing.

The data includes rich information about the characteristics of each case. In particular, it includes information about the offender (age, gender, race, past criminal history), the offense (severity of the offense, weapons enhancement, type of offense, number of counts), the sentence imposed by the judge, and the name of the judge who imposed it.

Pennsylvania provides sentencing guidelines that judges must consider when sentencing a felony or a misdemeanor offense. ${ }^{12}$ The guidelines assign two scores for each offense: (1) an offense gravity score (OGS), which ranges between 1 and 14 (where 14 represents the highest severity); and (2) a prior record score (PRS), which is based on the offender's prior criminal record and divided into

\footnotetext{
${ }^{9}$ The courts of common pleas are the courts of general jurisdiction in Pennsylvania. As such, they have jurisdiction over all felony and misdemeanor offenses See Pa. Const. Art. V, § 5, 42 Pa.C.S. § 931.

${ }^{10}$ Pennsylvania Rules of Criminal Procedure, Rule 130(A).

${ }^{11} 234$ Pa. Code Ch. 7, Rule 704.

${ }^{12}$ Our data contains three different sets of sentencing guidelines: the 5th, the 6th and the 6th revised guideline editions. The sentencing guidelines that apply to each offense are the ones that were in force on the date the offense was committed. Effective dates of the guidelines can be found on http://pcs.la.psu.edu/guidelines/sentencing/sentencing-guidelinesand-implementation-manuals/sentencing-guideline-effective-dates.
} 
eight reported categories. ${ }^{13}$ Both scores are reported for each offense. Based on the combination of these two scores, the guidelines provide a sentence recommendation.

Each case may include several counts (offenses). For each count, the judge must determine the minimum and the maximum sentence. ${ }^{14}$ The sentencing recommendation guideline sets a range for the minimum sentence between a lower and an upper limit, both stated in months of incarceration. The judge has discretion whether to impose a sentence within the guidelines range or not, subject to mandatory minimum and maximum statutory sentences, when those apply. ${ }^{15}$ In every case where the judge imposes a sentence outside the sentencing guidelines, she must provide a contemporaneous written statement of the reason or reasons for the deviation from the guidelines. The judge's discretion, however, goes beyond sentencing on each count, as she must decide whether to impose the sentence concurrently or consecutively with sentences for other counts in the same case. We exclude cases in which one of the offenses is subject to a mandatory life or death sentence, since the judge has no discretion in sentencing these offenses.

The sentencing guidelines categorize all offenses into five levels. Our analysis focuses on cases in which the maximum sentencing guideline level (based on offense gravity score and prior record score) among all counts of a specific case, is the highest, namely level five. We focus on these cases since they are the most visible to the public, and are more likely to earn some report in the media, and thus to affect the judge's reputation. Our data contains about 38,000 such cases (which accounts for about $5 \%$ of the total cases). For these offenses the average sentencing is about 67 months as compared to 18.7, 5.5, 1.3 and 0.2 months for offenses with level four, three, two and one, respectively.

Information on the judges was obtained from the Pennsylvania Manual. ${ }^{16}$ The Manual is published biennially, for years in which municipal elections take place. For each judge, the Manual provides information on when the judge was initially elected, and when he was re-elected. Once elected, judges stand for retention election every 10 years. ${ }^{17}$ In such elections, the name of the judge is submitted to the electors without party designation, to determine only the question whether he shall be retained in office. This vote takes place at the municipal election immediately preceding the expiration of the term of the judge. If a majority favors retention, the judge serves an additional ten-year term. ${ }^{18}$ Judges retire on the last day of the calendar year in which they reach the age of

\footnotetext{
${ }^{13}$ The categories are Repeat Violent Offender [REVOC], Repeat Felony 1 and Felony 2 Offender [RFEL], and point-based categories of $0,1,2,3,4$ and 5 . We code REVOC and RFEL as 6 point category.

${ }^{14}$ See 42 Pa.C.S.A. $§ 9756$. The minimum sentence may not be reduced through parole prior to its expiration.

${ }^{15}$ The guideline sentence cannot exceed the longest legal minimum sentence - which is one half the maximum allowed by law. When the guideline sentence exceeds such statutory limit then that limit is the longest guideline sentence recommendation. The court has no authority to impose a sentence lower than that required by a mandatory minimum provision established in statute. When the guideline range is lower than that required by a mandatory sentencing statute, the mandatory minimum requirement supersedes the sentence recommendation. When the sentence recommendation is higher than that required by a mandatory sentencing statute, the court shall consider the guideline sentence recommendation.

${ }^{16}$ The Pennsylvania Manual is published by the Pennsylvania Bureau of Publications. Electronic version of vol. 116-121 can be found on: http://www.portal.state.pa.us/portal/server.pt/community/pa_manual/1294.

${ }^{17}$ PA constitution, Article V, s. 15(a).

${ }^{18}$ PA constitution, Article V, s. 15(b).
} 
$70 .^{19}$

Using both the Pennsylvania Manual and the PCS, we were able to identify judge election and retention information for about $81 \%$ of the judges appearing in the PCS with offense of level 5 (410 judges out of 506), which also accounts for 91\% of all offenses (we managed to merge 34,527 out of 37,886 level five offenses).

\subsection{Variables}

Our dependent variable is Judge Sentence, which is defined to be the minimum sentence assigned to the offender by the judge in a specific case. Each case may include more than one count. The judge has discretion whether to impose the sentence on each count concurrently or consecutively with other sentences imposed in the same case. ${ }^{20}$ Therefore, our dependent variable is the sum of all consecutive sentences with the maximum of all the concurrent sentences imposed on the same offender in the case. Since the data contains some cases in which offenders were sentenced for hundreds of years, and we want to avoid biases resulting from outliers, we winsorize our dependent variable at the ninety-ninth percentile.

To test whether judges are affected by their past sentencing history, we define the variable Diff_Judge_Dist. This variable is equal to the difference between (i) the average sentences that the judge has imposed in the preceding year for all cases whose sentencing guideline level equals five and (ii) the average sentences imposed in the previous year in the judge's district for all offenses whose sentencing guideline level equals five.

To test whether judges behave differently when they are close to re-election, we define a variable labeled Prox_to_Elect to measure proximity to election. This variable is equal to 1 minus the number of days from the date of sentencing to the judge's nearest re-election, divided by 3650 . Thus, the variable values range from 0 and 1 , where 1 stands for most proximate elections to sentence. ${ }^{21}$ We also define an interaction term between the Prox_to_Elect variable and the Diff_Judge_Dist variable to test whether judges' current sentencing is affected by their previous year's sentences in a different way when they are close to their re-election.

Table 1 provides summary statistics of our dependent variable, our two main variables of interest and all of the covariates used in our analysis. Our data contains about 31,000 offense-year observations (for which we have full information) out of which $47 \%$ are observations for offenses that were dealt by judges whose experience by the time of sentencing is less than 10 years. The offenses that are included in our database were treated by the judges for which reelection was relevant, meaning that their age in the next reelections was younger than retirement age (which is 70). Our dependent variable, Judge Sentence, ranges between 0 and 366 with a mean of 67 months. An offender's age is on average 31 years old, 93\% of the crimes were committed by male offenders, $40 \%$ by white offenders. The average offense gravity score (which is the maximum OGS among all

\footnotetext{
${ }^{19}$ PA constitution, Article V, s. 16(b).

${ }^{20}$ See, for example, Commonweath v. Gonzalez DeJusus, 2010 PA Super 62, describing the range of discretion held by the trial court in determining whether sentences will be imposed concurrently or consecutively.

${ }^{21}$ As defined by Huber and Gordon, 2004.
} 
counts per case) is 10, and the offender's prior record score is on average 2 . In $16 \%$ of the cases an enhanced weapon was involved, and on average there were 3 counts per case. With respect to the disposition of the case prior to sentencing, $49 \%$ of the cases result in a negotiated guilty plea, $20 \%$ in negotiated guilty plea and the rest $31 \%$ in conviction on trial. On average, in each district there are about 64 cases with sentencing guideline level equal five, and about 6 different judges. Also on average each judge handles about 14 such cases each year. It should also be noted that the mean vote for judges who stand for reelection is $75 \%$, with variance equal to 0.073 . In fact, only two judges in our sample have failed to win a majority vote on reelection. As we show below, judges are nevertheless affected by retention elections in their sentencing decisions.

- Put Table 1 here -

\subsection{Testing the Hypothesis}

Our hypothesis suggests that we should expect inexperienced judges (defined as judges with less than 10 years of experience as judges) to be affected by the difference between the average sentences they imposed last year and the sentences imposed by their colleagues in the same district. We also expect the effect to become more pronounced as judges approach election. To test this hypothesis we run the following three models:

(1) JudgeSentence $=\alpha_{1}+\beta$ ProxtoElect $_{j, t}+\gamma X_{i, t}+\delta_{j}+\lambda_{t}+\varepsilon_{i, j}$

(2) JudgeSentence $=\alpha_{1}+\beta$ DiffJudgeDist ${ }_{j, t}+\gamma X_{i, t}+\delta_{j}+\lambda_{t}+\varepsilon_{i, j}$

(3) JudgeSentence $=\alpha_{1}+\beta_{1}$ ProxtoElect $_{j, t}+\beta_{2}$ DiffJudgeDist $_{j, t}+\beta_{3}$ ProxtoElect $_{j, t} \times$ Diff JudgeDist $_{j, t}$ $+\gamma X_{i, t}+\delta_{j}+\lambda_{t}+\varepsilon_{i, j}$

where $i$ is an indicator for the case/offender, $j$ for the judge, and $t$ for the year of sentence. The matrix $X_{i, t}$ includes offender's characteristics such as: age, gender, an indicator if the offender is white, and prior record score; offense's characteristics such as: gravity of the offense, an indicator whether weapon was involved, the number of counts in each case, indicator variables for negotiated and non-negotiated guilty plea (where the baseline is conviction on trial); and two measures for the district (1) the number of judges in a specific district, and (2) the number of cases with sentencing guideline level equal to five handled last year in that district. We also generate indicators for the sentencing guideline editions.

To control for judge's ideology we employ judge fixed effect, which accounts for all judges' characteristics that do not change over time. Since judges do not move from one district to another, controlling for judge fixed effect controls also for the unobserved heterogeneity in districts. We also control for year and for offense statutory grade dummies. Our standard errors are clustered by judges. 
Table 2, Columns (1)-(3), provide the results of our first model. The regression is run first for all judges and then separately for judges with less than 10 years of experience and for judges with more than 10 years of experience. We find the coefficient on Prox_to_Elect to be indistinguishable from zero for all judges as well as for inexperienced and experienced judges. Our findings suggest that judges' current sentencing are not affected by proximity to election regardless of the judges' experience.

Columns (4)-(6) provide the results of our second model. As in the previous model, the regression is first run for all judges and then it is run separately for inexperienced and experienced judges. We find the coefficient on Diff_Judge_Dist to be indistinguishable from zero for all judges as well as for inexperienced and experienced judges. Hence, we find no effect of a judge's last year's sentencing on her current sentence.

Columns (7)-(9) provide the results of our third model. Here we introduce an interaction term between Prox_to_Elect and Diff_Judge_Dist. Column 7 shows that the coefficients on Prox_to_Elect, Diff_Judge_Dist, and on their interaction term are all indistinguishable from zero when we run the regression on all judges, regardless of their experience. However, once we run this model separately for inexperienced judges we get that although Prox_to_Elect and Diff_Judge_Dist is positive but insignificant the interaction term is negative and statistically significant (with a coefficient of -0.332 significant at the $5 \%$ level). This suggests that judges tend to impose sentences 'against their prior record', but they do so only when they approach retention elections. When we run the regression separately for experienced judges we do not find such an association.

\section{- Put Table 2 here -}

This effect is not small. Table 5, Column 1, (after Table 4, below) provides the magnitude of the effect in months on sentencing, for judges who are inexperienced, a year before election (with Prox_to_Elect equal 0.9) and with Diff_Judge_Dist values in the 10th, 25th, 75th and 90th quantile (with Diff_Judge_Dist equals -40, -16, 12 and 29 respectively). Our prediction suggests that a year before standing for reelection, a judge with Diff_Judge_Dist in the 10th (25th) quantile would raise the length of incarceration by 9 (5) months. Similarly judges with Diff_Judge_Dist in the 90th (75th) quantile would lower the length of incarceration by 2 months (1), respectively.

Most of the other covariates have signs that are consistent with findings by prior literature. Male offenders receive longer sentences than female offenders, and white offenders receive lower sentences than non-whites. As expected, when the offense has a higher OGS or a higher PRS the length of incarceration is longer. When enhanced weapon is used sentences are higher. Negotiated plea and non-negotiated plea have a negative effect on sentencing. Guideline editions have a negative effect on judge sentences (suggesting that the 6th guideline editions are less stringent than the 5th guideline edition) and the number of counts on each case has a positive and statistically significant effect. The number of judges in a district has negative and significant effect on sentencing only for experienced judges. We find offender age, and the number of similar cases handled last year in the same district to have no statistically significant effect. 


\subsection{Discussion and Alternative Specifications of the Model}

Table 3 provides the results of regressing Judge Sentence on Proximity to Election Squared. This expresses our expectation that the effect of proximity to election should not only become larger when approaching election, but also that this effect is convex. Put differently, we expect any change in the effect of proximity to election to become more pronounced as elections becomes near . The results show similar pattern to the one we observed before. Table 5, Column 2 (after Table 4, below) provides the magnitude of the effect for a judge who is one year before election with Diff_Judge_Dist value in the 10th, 25th, 75th and 90th quantile (in a similar manner to what we did for Table 2 Column 8). We find that one year before reelection, a judge with Diff_Judge_Dist in the 10th and 25th quintile would raise the length of incarceration by 9 and 3 months respectively and would lower it by 3 and 7 months if his Diff_Judge_Dist is in the 75th and 90th quantile.

- Put Table 3 here -

On average, judges in our data have about 14 different cases with sentencing guideline whose level equals five. However, $6 \%$ of the judges decided less than 1 'level five' case in a specific year and 14\% decided less than 3 'level five' cases in a given year. Therefore, Table 4 repeats Table 3, once for all cases where judges handled more than one case in the previous year (Columns 1-3), and once for all cases where judges handled more than three cases in the previous year (Columns 4-6). The last three columns (Columns 7-9) present the results when we weight our regression by the number of cases that judges handled in the previous year. We get similar patterns to the ones obtained in Table 2 and Table 3.

- Put Table 4 here -

Table 5, Column 3, 4 and 5 provide the magnitude of the effect for inexperienced judges. We find the magnitude of the effects is a bit larger, with the largest effect obtained in the weighted regressions.

- Put Table 5 here -

Finally, to the extent that prosecutors and defendants expect approaching judicial elections to affect the expected sentence, such expectation might affect prosecutors' decisions in filing charges with minimum sentences or their plea bargain decisions (For recent literature discussing the effects of prosecutorial discretion on sentencing see Bjerk, 2005; Ulmer, Kurlychek, and Kramer, 2007; Starr and Rehavy, 2013; Yang, 2014). This might raise a concern for a selection bias effect. However, we find no evidence for such an effect in our data. In particular, focusing on judges with less than 10 years of tenure - the judges that we show to be most influenced by the timing of judicial 
elections - we find that the percentage of plea deals is 0.503 for cases that are in the bottom decile in terms of proximity to elections and 0.48 in cases that are in the top decile in terms of proximity to elections. Furthermore, in a regression of the likelihood of a plea bargain on all the characteristics included in the regression of Table 2, the coefficients of proximity to elections and its interaction with Diff_Judge_Dist are not statistically significant.

Moreover, even if the election cycle does change somewhat the mix of cases with and without plea bargains, the presence of such an effect does not undermine our identification of the effect of the election cycle on judges' sentencing in a given case. We checked and verified that judges are facing a mix of cases with and without plea bargains throughout the judicial election cycle. We also checked and verified that the same is true for cases with and without mandatory minimum sentencing. Furthermore, our analysis controls for various characteristics of cases brought, including whether there was a plea bargain in the case. Therefore, our analysis shows that, for any given mix of cases, the judicial election cycle affects sentencing decisions in given cases. To be sure, our finding of an effect of the judicial election cycle on sentencing decisions suggests that it may be worthwhile for future work to examine how the judicial election cycle affects the choices of agents other than judges, such as prosecutors and defendants. Such future work may be useful for understanding how judicial election cycles affect sentencing outcomes.

\section{Conclusion}

This paper developed a dynamic reputation model of judicial decisions over the elections cycle. This approach models a judge's reputation as a belief held by the public (or any other appointing principal) concerning the judge's attitudes and preferences. The public's belief is updated based on the judge's decisions, and consequently affects the judge's prospects of reelection or reappointment. Since the judge cares about being reelected or reappointed, her decision in each case may be affected by her effort to influence the public's perceptions.

The dynamic reputation approach predicts a negative serial correlation, between a judge's past decisions and the present decision she makes, on any issue that is of importance to the public. Our empirical examination of Pennsylvania courts' criminal sentences demonstrated a negative correlation for less experienced judges as they approach retention elections. These findings are consistent with the predictions of the reputation model.

The reputation model casts some doubt over the value of past decisions as a predictor of future decisions. ${ }^{22}$ Judges' $^{\prime}$ past decisions do not necessarily predict how they will decide future cases. On the contrary, judicial decisions may exhibit negative correlation with their past decisions.

Because our findings are consistent with the view that approaching judicial elections influence judges' decisions, they are broadly consistent with the realistic approach to judging. Furthermore, our empirical evidence on the correlation between a judge's current and past decisions, identifies the dynamic incentive effects of judicial elections, as distinguished from their static selection effects. Our work suggests that analysis of dynamic effects is necessary for a complete picture of how judicial

\footnotetext{
${ }^{22}$ See review in Brace, Langer and Hall (2000) p. 390-391
} 
elections influence the decisions of judges. 


\section{Appendix}

Claim 3. There are only two pure strategy equilibria. One where both types of judges always impose a light sentence and another where both types of judges impose a severe sentence.

Proof. As explained above, both of the equilibria described above are sustained by the public's belief that any deviation indicates that the judge is lenient. Claim 1 implies that all the combinations in which the lenient type sometimes imposes a more severe sentence than the strict type can be ruled out. All other separating equilibria can also be ruled out because they imply that a lenient type is identified as such with a positive probability. This implies that if $V$ is large enough, then the lenient type would benefit from deviating and rendering the same decision that the strict type would render. Finally, for both types of judges to always impose an inappropriate decision cannot be an equilibrium for the same reason that for both judges to always render the appropriate decision cannot be an equilibrium. Namely, in such a case the judges' decisions don't affect the pubic's belief about their type, and so both types of judges would benefit from deviating and rendering the decision they prefer. 


\section{References}

[1] David Bjerk, 2005. Making the Crime Fit the Penalty: The Role of Prosecutorial Discretion Under Mandatory Minimum Sentencing. Journal of Law and Economics 48:591-625

[2] Boyea Brent D., 2010. Does Seniority Matter? The Conditional Influence of State Methods of Judicial Retention. Social Science Quarterly 91: 209-227

[3] Brace Paul R., and Melinda Gann Hall. 1997. The Interplay of Preferences, Case Facts, Context, and Rules in the Politics of Judicial Choice. Journal of Politics 59: 1206-1231

[4] Brace Paul R., Laura Langer and Melinda Gann Hall. 2000. Measuring the Preferences of State Supreme Court Judges. Journal of Politics. 62: 387-413.

[5] Brooks, Richard R.W., and Steven Raphael. 2002. Life Term or Death Sentences: The Uneasy Relationship between Judicial Elections and Capital Punishment. Journal of Criminal Law and Criminology. 92: 609-640.

[6] Caldarone Richard P., Brandice Canes-Wrone, Tom S. Clark, 2009. Partisan Labels and Democratic Accountability: An Analysis of State Supreme Court Abortion Decisions. The Journal of Politics 71: 560-573.

[7] Canes-Wrone Brandice, Clark Tom S., and Jee-Kwang Park. 2012. Judicial Independence and Retention Elections. Journal of Law, Economics and Organization 28: 211-234.

[8] Cho, In-Koo, and David M. Kreps. 1987. Signaling Games and Stable Equilibria. The Quarterly Journal of Economics 102: 179-221.

[9] Choi, Stephen J., G. Mitu Gulati, and Eric A. Posner. 2010. Professionals or Politicians: The Uncertain Empirical Case for an Elected Rather than Appointed Judiciary. Journal of Law, Economics and Organization. 26: 290-336.

[10] Cullen, Francis T., Bonnie S. Fisher, and Brandon K. Applegate. 2000. Public Opinion about Punishment and Correction. Crime and Justice 27: 1-79.

[11] Ely, J., and Valimaki, J. 2003. Bad Reputation. Quarterly Journal of Economics 118: 785814.

[12] Epstein, Lee, Valerie Hoekstra, Jeffrey A. Segal, and Harold J. Spaeth. 1998. Do Political Preferences Change: A Longitudinal Study of U.S. Supreme Court Justices. Journal of Politics 60: 801-18.

[13] Epstein, Lee, William M. Landes, and Richard A. Posner. 2013. The Behavior of Federal Judges (Oxford).

[14] Hall, Melinda G.. 1992. Electoral Politics and Strategic Voting in State Supreme Courts. Journal of Politics 54: 427-446. 
[15] Hall, Melinda G.. 1995. Justices as Representatives: Elections and Judicial Politics in the American States. American Politics Quarterly 23: 485-503.

[16] Gordon Sanford C. and Gregory A. Huber. 2007. The Effect of Electoral Competitiveness on Incumbent Behavior. Quarterly Journal of Political Science. 2: 107-138.

[17] Helland, Eric, and Alexander Tabarrok. 2002. The Effect of Electoral Institutions on Tort Awards. American Law and Economics Review. 4:341-470.

[18] Huber, Gregory A., and Sanford C. Gordon. 2004. Accountability and Coercion: Is Justice Blind When It Runs for Office?. American Journal of Political Science. 8: 247-263.

[19] Huber, Gregory A., and Sanford C. Gordon. 2007a. Directing Retribution: On the Political Control of Lower Court Judges. Journal of Law, Economics and Organization. 23: 386-420.

[20] Klement Alon and Zvika Neeman. 2013. Does Information about Arbitrators' Win/Loss Ratio Improve Their Accuracy?. Journal of Legal Studies 42: 369-397

[21] Lim, Claire S.H., 2013. Preferences and Incentives of Appointed Public Officials: Evidence from State Trial Court Judges. American Economic Review 103: 1360-1397.

[22] Martin, Andrew D., and Kevin M. Quinn. 2002. Dynamic Ideal Point Estimation via Markov Chain Monte Carlo for the U.S. Supreme Court, 1953-1999. Political Analysis 10: 134-53.

[23] Martin, Andrew D., and Kevin M. Quinn. 2007. Assessing Preference Change on the U.S. Supreme Court. Journal of Law, Economics and Organization 23: 365-85.

[24] Miceli, Thomas J., and Metin M. Cosgel. 1994. Reputation and Judicial DecisionMaking. Journal of Economic Behavior and Organization 23:31-51.

[25] Mailath, George J. and Larry Samuelson. 2006. Repeated Games and Reputations: LongRun Relationships (Oxford).

[26] Shepherd, Joanna M. 2009. The Influence of Retention Politics on Judges' Voting. Journal of Legal Studies 38:169-206.

[27] Shepherd, Joanna M. 2009a. Money, Politics and Impartial Justice. Duke Law Journal 58: 623-685.

[28] Shepherd, Joanna M. 2009b. Are Appointed Judges Strategic Too?. Duke Law Journal 58: 1589-1626.

[29] Shepherd, Joanna M. 2011. Measuring Maximizing Judges: Empirical Legal Studies, Public Choice Theory, and Judicial Behavior. University of Illinois Law Review 2011: 1753-1766. 
[30] Starr, Sonja B. and M. Marit Rehavi. 2013. Mandatory Sentencing and Racial Disparity: Assessing the Role of Prosecutors and the Effect of Booker. Yale Law Journal 123:2-80.

[31] Ulmer, Jeffery T. , Megan C. Kurlychek and John H. Kramer. 2007. Prosecutorial Discretion and the Imposition of Mandatory Minimum Sentences. Journal of Research in Crime and Delinquency 44:427-458.

[32] Yang, Crystal S.. 2014. Have Inter-Judge Sentencing Disparaties Increasesed in an Advisory Guidelines Regime? Evidence from Booker. New York University Law Review (forthcoming). 
Table 1: Summary Statistics

\begin{tabular}{|c|c|c|c|}
\hline & (1) & (2) & (3) \\
\hline & All & $0-10$ & $10+$ \\
\hline \multirow[t]{2}{*}{ Judge Sentence } & 67.228 & 64.090 & 69.994 \\
\hline & $(70.594)$ & $(68.649)$ & $(72.155)$ \\
\hline \multirow[t]{2}{*}{ Proximity to Election } & 0.495 & 0.488 & 0.501 \\
\hline & $(0.275)$ & $(0.245)$ & $(0.298)$ \\
\hline \multirow[t]{2}{*}{ Diff Judge-District } & 0.372 & -1.834 & 2.135 \\
\hline & $(27.964)$ & $(30.149)$ & $(2553)$ \\
\hline \multirow[t]{2}{*}{ Offender Age } & 30.873 & 30.572 & 31.139 \\
\hline & $(10.839)$ & $(10.726)$ & $(10.932)$ \\
\hline \multirow[t]{2}{*}{ Offender Male } & 0.927 & 0.928 & 0.926 \\
\hline & $(0.260)$ & $(0.258)$ & $(0.262)$ \\
\hline \multirow[t]{2}{*}{ Offender White } & 0.404 & 0.376 & 0.429 \\
\hline & $(0.491)$ & $(0.484)$ & $(0.495)$ \\
\hline \multirow[t]{2}{*}{ Max OGS } & 10.156 & 10.081 & 10.223 \\
\hline & $(1.637)$ & $(1.595)$ & $(1.671)$ \\
\hline \multirow[t]{2}{*}{ Offender PRS } & 1.996 & 1.976 & 2.013 \\
\hline & $(2.214)$ & $(2.199)$ & $(2.227)$ \\
\hline \multirow[t]{2}{*}{ Enhanced Weapon } & 0.157 & 0.142 & 0.171 \\
\hline & $(0.365)$ & $(0.349)$ & $(0.377)$ \\
\hline \multirow[t]{2}{*}{ Counts per Case } & 3.140 & 2.957 & 3.302 \\
\hline & $(4.946)$ & $(3.693)$ & $(5.826)$ \\
\hline \multirow[t]{2}{*}{ No.cases by Judge Last Year } & 14.188 & 13.609 & 14.641 \\
\hline & $(19.234)$ & $(23.147)$ & $(15.499)$ \\
\hline \multirow[t]{2}{*}{ Non Negotiated } & 0.198 & 0.215 & 0.183 \\
\hline & $(0.382)$ & $(0.397)$ & $(0.368)$ \\
\hline \multirow[t]{2}{*}{ Negotiated Guilty } & 0.491 & 0.472 & 0.508 \\
\hline & $(0.500)$ & $(0.499)$ & $(0.499)$ \\
\hline \multirow[t]{2}{*}{ No.cases in District } & 63.591 & 58.681 & 67.376 \\
\hline & $(165.748)$ & $(142.652)$ & $(181.732)$ \\
\hline \multirow[t]{2}{*}{ No. of Judges in Dis } & 5.708 & 5.870 & 5.582 \\
\hline & $(7.340)$ & $(7.531)$ & $(7.201)$ \\
\hline \multirow[t]{2}{*}{ Guideline Ed. 6th } & 0.441 & 0.464 & 0.421 \\
\hline & $(0.497)$ & $(0.499)$ & $(0.494)$ \\
\hline \multirow[t]{2}{*}{ Guideline Ed. 6th Re } & 0.115 & 0.142 & 0.091 \\
\hline & $(0.319)$ & $(0.349)$ & $(0.287)$ \\
\hline Number of Obs. & 31,040 & 14,543 & 16,497 \\
\hline
\end{tabular}


Table 2: Association between judge sentence, proximity to election, judge-district diff and its interaction

\begin{tabular}{|c|c|c|c|c|c|c|c|c|c|}
\hline & (1) & (2) & (3) & (4) & (5) & (6) & (7) & (8) & (9) \\
\hline & All & $0-10$ & $10+$ & All & $0-10$ & $10+$ & All & $0-10$ & $10+$ \\
\hline \multirow[t]{2}{*}{ Proximity to Election } & 0.913 & -1.974 & 1.763 & & & & 1.229 & 3.103 & 1.638 \\
\hline & $(1.798)$ & $(4.564)$ & $(2.064)$ & & & & $(1.910)$ & $(6.992)$ & $(2.021)$ \\
\hline \multirow[t]{2}{*}{ Diff Judge-District } & & & & 0.016 & -0.018 & -0.007 & 0.062 & 0.140 & -0.098 \\
\hline & & & & $(0.024)$ & $(0.042)$ & $(0.024)$ & $(0.047)$ & $(0.091)$ & $(0.065)$ \\
\hline \multirow[t]{2}{*}{ Prox X Diff } & & & & & & & -0.105 & $-0.332 * *$ & 0.126 \\
\hline & & & & & & & $(0.076)$ & $(0.143)$ & $(0.101)$ \\
\hline \multirow[t]{2}{*}{ Offender Age } & $0.332^{*}$ & 0.283 & $0.417^{*}$ & $0.316^{*}$ & 0.127 & $0.470^{* *}$ & 0.218 & 0.133 & 0.302 \\
\hline & $(0.184)$ & $(0.276)$ & $(0.222)$ & $(0.188)$ & $(0.319)$ & $(0.224)$ & $(0.203)$ & $(0.323)$ & $(0.240)$ \\
\hline \multirow[t]{2}{*}{ Offender Age Squared } & $-0.006^{* *}$ & -0.005 & $-0.006^{* *}$ & $-0.005^{* *}$ & -0.003 & $-0.007 * *$ & -0.004 & -0.004 & -0.005 \\
\hline & $(0.002)$ & $(0.004)$ & $(0.003)$ & $(0.002)$ & $(0.004)$ & $(0.003)$ & $(0.003)$ & $(0.004)$ & $(0.003)$ \\
\hline \multirow[t]{2}{*}{ Offender Age Missing } & 10.830 & -0.546 & 12.500 & 1.400 & -20.979 & 11.352 & -1.217 & -21.826 & 6.891 \\
\hline & $(12.429)$ & $(24.441)$ & $(13.039)$ & $(15.400)$ & $(33.038)$ & $(16.786)$ & $(15.047)$ & $(32.339)$ & $(15.695)$ \\
\hline \multirow[t]{2}{*}{ Offender Male } & $14.431^{* * *}$ & $14.371^{* * *}$ & $14.299^{* * *}$ & $13.955^{* * *}$ & $14.427^{* * *}$ & $13.854^{* * *}$ & $14.360^{* * *}$ & $14.340^{* * *}$ & $14.403^{* * *}$ \\
\hline & $(1.221)$ & $(1.628)$ & $(1.678)$ & $(1.200)$ & $(1.721)$ & $(1.603)$ & $(1.288)$ & $(1.733)$ & $(1.800)$ \\
\hline \multirow[t]{2}{*}{ Offender White } & $-5.621^{* * *}$ & $-7.239^{* * *}$ & $-4.668^{* * *}$ & $-5.622^{* * *}$ & $-7.230^{* * *}$ & $-4.914^{* * *}$ & $-5.740^{* * *}$ & $-6.931 * * *$ & $-5.108 * * *$ \\
\hline & $(0.731)$ & $(1.211)$ & $(0.916)$ & $(0.757)$ & $(1.372)$ & $(0.963)$ & $(0.775)$ & $(1.367)$ & $(0.972)$ \\
\hline \multirow[t]{2}{*}{ Max OGS } & $21.909^{* * *}$ & $21.633^{* * *}$ & $21.829^{* * *}$ & $22.671^{* * *}$ & $22.510^{* * *}$ & $22.572^{* * *}$ & $22.718^{* * *}$ & $22.582^{* * *}$ & $22.539 * * *$ \\
\hline & $(0.477)$ & $(0.620)$ & $(0.657)$ & $(0.463)$ & $(0.669)$ & $(0.604)$ & $(0.498)$ & $(0.659)$ & $(0.678)$ \\
\hline \multirow[t]{2}{*}{ Offender PRS } & $9.673^{* * *}$ & $9.785^{* * *}$ & $9.501^{* * *}$ & $9.752^{* * *}$ & $9.935^{* * *}$ & $9.566^{* * *}$ & $9.831^{* * *}$ & $9.918^{* * *}$ & $9.681^{* * *}$ \\
\hline & $(0.227)$ & $(0.290)$ & $(0.322)$ & $(0.230)$ & $(0.315)$ & $(0.308)$ & $(0.249)$ & $(0.322)$ & $(0.349)$ \\
\hline \multirow[t]{2}{*}{ Enhanced Weapon } & $33.285^{* * *}$ & $33.763^{* * *}$ & $31.975^{* * *}$ & $34.064^{* * *}$ & $34.827^{* * *}$ & $32.874^{* * *}$ & $34.621^{* * *}$ & $34.781^{* * *}$ & $33.554^{* * *}$ \\
\hline & $(1.537)$ & $(2.162)$ & $(1.656)$ & $(1.516)$ & $(2.302)$ & $(1.660)$ & $(1.651)$ & $(2.281)$ & $(1.853)$ \\
\hline \multirow[t]{2}{*}{ Counts per Case } & $2.875^{* * *}$ & $4.401^{* * *}$ & $2.345^{* * *}$ & $2.832^{* * *}$ & $4.402^{* * *}$ & $2.387^{* * *}$ & $2.724^{* * *}$ & $4.373^{* * *}$ & $2.210^{* * *}$ \\
\hline & $(0.667)$ & $(0.676)$ & $(0.695)$ & $(0.668)$ & $(0.761)$ & $(0.694)$ & $(0.665)$ & $(0.759)$ & $(0.669)$ \\
\hline \multirow[t]{2}{*}{ Nonnego_c } & $-13.051 * * *$ & $-12.002^{* * *}$ & $-14.092^{* * *}$ & $-13.521 * * *$ & $-13.922^{* * *}$ & $-13.461^{* * *}$ & $-13.637^{* * *}$ & $-13.881^{* * *}$ & $-13.480^{* * *}$ \\
\hline & $(1.473)$ & $(2.288)$ & $(1.960)$ & $(1.416)$ & $(2.584)$ & $(1.507)$ & $(1.573)$ & $(2.637)$ & $(1.789)$ \\
\hline \multirow[t]{2}{*}{ Negotiated Guilty } & $-16.215^{* * *}$ & $-14.515^{* * *}$ & $-17.715^{* * *}$ & $-16.121^{* * *}$ & $-14.699 * * *$ & $-17.070 * * *$ & $-16.201 * * *$ & $-14.778^{* * *}$ & $-17.273^{* * *}$ \\
\hline & $(1.373)$ & (1.937) & (1.797) & $(1.291)$ & $(2.065)$ & $(1.538)$ & $(1.374)$ & (2.095) & $(1.683)$ \\
\hline \multirow[t]{2}{*}{ No.cases in District Last Year } & 0.002 & -0.002 & -0.001 & 0.001 & 0.001 & -0.002 & 0.002 & -0.002 & 0.004 \\
\hline & $(0.005)$ & $(0.008)$ & $(0.006)$ & $(0.004)$ & $(0.007)$ & $(0.005)$ & $(0.004)$ & $(0.007)$ & $(0.006)$ \\
\hline \multirow[t]{2}{*}{ No. of Judges in District } & $-0.371^{*}$ & 0.025 & $-0.393^{*}$ & $-0.320^{*}$ & 0.126 & $-0.424^{*}$ & -0.250 & 0.258 & -0.369 \\
\hline & $(0.211)$ & $(0.328)$ & $(0.237)$ & $(0.193)$ & $(0.342)$ & $(0.221)$ & $(0.201)$ & $(0.336)$ & $(0.234)$ \\
\hline \multirow[t]{2}{*}{ Guideline Ed. 6th } & $-7.930 * * *$ & $-8.810^{* * *}$ & $-6.836^{* * *}$ & $-7.934^{* * *}$ & $-7.818^{* * *}$ & $-7.676^{* * *}$ & $-7.559^{* * *}$ & $-8.009^{* * *}$ & $-6.825 * * *$ \\
\hline & $(1.626)$ & $(2.201)$ & $(2.234)$ & $(1.578)$ & $(2.377)$ & $(2.024)$ & $(1.670)$ & $(2.390)$ & $(2.235)$ \\
\hline \multirow[t]{2}{*}{ Guideline Ed. 6th Revised } & $-13.374^{* * *}$ & $-11.578^{* * *}$ & $-15.177^{* * *}$ & $-13.521^{* * *}$ & $-10.843^{* * *}$ & $-15.379 * * *$ & $-13.204^{* * *}$ & $-11.117^{* * *}$ & $-15.200^{* * *}$ \\
\hline & $(2.327)$ & $(3.074)$ & $(3.146)$ & $(2.280)$ & $(3.195)$ & $(3.043)$ & $(2.347)$ & $(3.172)$ & $(3.167)$ \\
\hline Adjusted R-squared & 0.4953 & 0.5173 & 0.4886 & 0.5023 & 0.5210 & 0.5001 & 0.5029 & 0.5231 & 0.5003 \\
\hline No. of Obs & 31,040 & 14,543 & 16,497 & 30,190 & 12,098 & 18,092 & 26,849 & 11,923 & 14,926 \\
\hline
\end{tabular}

Note: Standard errors in parentheses and are clustered by Judge. Stars denote the level of statistical significance ${ }^{*} p<0.1,{ }^{* *} p<0.05,{ }^{* * *} p<0.01$. We $^{*}$ control for Judge, Year and Offense Statutory Grade dummies. 
Table 3: Different Specification for Proximity to Election

\begin{tabular}{lccc}
\hline \hline & $(1)$ & $(2)$ & $(3)$ \\
& All & $0-10$ & $10+$ \\
\hline Proximity to Election Squared & 1.936 & -0.100 & 1.730 \\
& $(1.882)$ & $(8.215)$ & $(1.930)$ \\
& & & \\
Diff Judge-District & 0.043 & 0.073 & -0.066 \\
& $(0.038)$ & $(0.066)$ & $(0.049)$ \\
Prox Square X Diff & -0.106 & $-0.342^{* *}$ & 0.091 \\
& $(0.078)$ & $(0.142)$ & $(0.098)$ \\
\hline Adjusted R-squared & 0.5030 & 0.5231 & 0.5002 \\
No. of Obs & 26,849 & 11,923 & 14,926 \\
\hline \hline
\end{tabular}

Note: Standard errors in parentheses and are clustered by Judge. Stars denote the level of statistical significance * $p<0.1,{ }^{* *} p<0.05,{ }^{* * *} p<0.01$. We control for Judge, Year and Offense Statutory Grade dummies. We also control for all other offender and offense covariates (not shown in the table) 
Table 4: Sub samples defined by number of cases handled by judge last year using proximity squared

\begin{tabular}{|c|c|c|c|c|c|c|c|c|c|}
\hline & \multicolumn{3}{|c|}{ More than one case } & \multicolumn{3}{|c|}{ More than three cases } & \multicolumn{3}{|c|}{ weighted by no of cases last year } \\
\hline & (1) & $(2)$ & $(3)$ & $(4)$ & $(5)$ & (6) & $(7)$ & $(8)$ & $(9)$ \\
\hline & All & $0-10$ & $10+$ & All & $0-10$ & $10+$ & All & $0-10$ & $10+$ \\
\hline \multirow[t]{2}{*}{ Proximity to Election Squared } & 1.763 & 0.604 & 1.183 & 1.800 & 3.535 & 1.179 & 0.995 & 3.298 & 0.158 \\
\hline & $(1.938)$ & $(8.637)$ & $(2.016)$ & $(1.937)$ & $(9.204)$ & $(2.017)$ & $(2.152)$ & $(17.211)$ & $(2.311)$ \\
\hline \multirow[t]{2}{*}{ Diff Judge-District } & 0.039 & 0.088 & -0.084 & $0.081^{*}$ & $0.171^{*}$ & -0.056 & $0.142^{* * *}$ & $0.272^{* *}$ & -0.018 \\
\hline & $(0.042)$ & $(0.072)$ & $(0.052)$ & $(0.047)$ & $(0.092)$ & $(0.058)$ & $(0.053)$ & $(0.109)$ & $(0.075)$ \\
\hline \multirow[t]{2}{*}{ Prox Squared X Diff } & -0.124 & $-0.379^{* *}$ & 0.080 & $-0.199 * *$ & $-0.553^{* * *}$ & 0.036 & $-0.347^{* * *}$ & $-0.812^{* * *}$ & -0.144 \\
\hline & $(0.084)$ & $(0.150)$ & $(0.105)$ & $(0.096)$ & $(0.185)$ & $(0.118)$ & $(0.126)$ & $(0.280)$ & $(0.149)$ \\
\hline Adjusted R-squared & 0.5019 & 0.5223 & 0.4990 & 0.5011 & 0.5241 & 0.4961 & 0.5008 & 0.5150 & 0.4953 \\
\hline No. of Obs & 26,287 & 11,643 & 14,644 & 24,976 & 10,913 & 14,063 & 26,849 & 11,923 & 14,926 \\
\hline
\end{tabular}

Note: Standard errors in parentheses and are clustered by Judge. Stars denote the level of statistical significance ${ }^{*} p<0.1,{ }^{* *}$ $p<0.05,{ }^{* * *} p<0.01$. We control for Judge, Year and Offense Statutory Grade dummies. We also control for all other offender and offense covariates (not shown in the table) 
Table 5: How Large is the Effect? (in months for inexperienced judges)

\begin{tabular}{|c|c|c|c|c|c|}
\hline & $\begin{array}{c}\text { (1) } \\
\text { Table } 2 \\
\text { Column } 8\end{array}$ & $\begin{array}{c}\text { (2) } \\
\text { Table } 3 \\
\text { Column } 2\end{array}$ & $\begin{array}{c}\text { (3) } \\
\text { Table } 4 \\
\text { Column } 2\end{array}$ & $\begin{array}{c}(4) \\
\text { Table } 4 \\
\text { Column } 5\end{array}$ & $\begin{array}{c}(5) \\
\text { Table } 4 \\
\text { Column } 8\end{array}$ \\
\hline $\begin{array}{l}10 \text { Percentile } \\
\text { (Diff Judge-District }=-40 \text { ) }\end{array}$ & 9 & 9 & 9 & 14 & 18 \\
\hline $\begin{array}{l}25 \text { Percentile } \\
\text { (Diff Judge-District }=-16 \text { ) }\end{array}$ & 5 & 3 & 4 & 7 & 9 \\
\hline $\begin{array}{l}75 \text { Percentile } \\
\text { (Diff judge-District=12) }\end{array}$ & 1 & -3 & -2 & -1 & -2 \\
\hline $\begin{array}{l}90 \text { Percentile } \\
\text { (Diff judge-District }=12 \text { ) }\end{array}$ & -2 & -7 & -6 & -5 & -9 \\
\hline
\end{tabular}

